\title{
The Anti-melanogenesis Activities of Some Selected Brown Macroalgae from Northern Coasts of the Persian Gulf
}

\author{
Foroogh Namjooyan ${ }^{1}$ \\ https://orcid.org/0000-0002-3171-479X \\ Massoumeh Farasat ${ }^{2}$ \\ https://orcid.org/0000-0002-4425-9351 \\ Mojtaba Alishahi ${ }^{3}$ \\ Alireza Jahangiri ${ }^{4}$ \\ Hamideh Mousavi ${ }^{5^{*}}$ \\ https://orcid.org/0000-0001-9451-2645
}

\begin{abstract}
11 Ahvaz Jundishapur University of Medical Sciences; School of Pharmacy; Marine Pharmaceutical Research Center; Pharmacognosy Department; Ahvaz; Khuzestan; Iran; '2Islamic Azad University; Ahvaz branch; Department of Agronomy; Ahvaz; Khuzestan; Iran; ${ }^{3}$ Shahid Chamran University of Ahvaz; Faculty of veterinary Medicine; Ahvaz; Khuzestan; Iran; ${ }^{4}$ Ahvaz Jundishapur University of Medical Sciences; School of pharmacy; Medicinal Chemistry Department; Ahvaz; Khuzestan; Iran; ${ }^{5}$ Ahvaz Jundishapur University of Medical Sciences; School of pharmacy; Ahvaz; khuzestan; Iran.
\end{abstract}

Received: 2018.01.23; Accepted: 2019.03.23.

* Correspondence: mousavihamideh@yahoo.com; Tel.: +98-9163070484 (H.M.)

\section{HIGHLIGHTS}

- P. boergesenii exhibited higher in vitro anti- tyrosinase activity compared to other algae.

- $\quad$ P. boergesenii inhibited melanin synthesis higher in comparison to other tested algae.

- The type of algae, place and time of collection can affect the inhibitory activities.

Abstract: Melanogenesis is a biological process which led to the synthesis of melanin pigment. Abnormal melanin production results in melasma, solar lentigo, post inflammatory melanoderma, etc. In this study, we examined the potential inhibitory effects of 17 brown macroalgae from Persian Gulf on melanogenesis. The effects of various concentrations $(100,250$ and $500 \mu \mathrm{g} / \mathrm{mL}$ ) of methanolic extracts of macroalgae belonging to four genera (including: Padina, Colpomonia, Cystoseira and Sargassum) were studied on oxidation of L-Dopa by mushroom tyrosinase. Subsequently, the activity of macroalgae with high 
inhibitory effect on monophenolase activity of mushroom tyrosinase and zebrafish was investigated using L-tyrosine as a substrate. Anti-melanogenesis effects of algae extracts were studied on zebrafish as an alternative in vivo model. Kojic acid was used as a positive control. All the tested macroalgae showed inhibitory effect on activities of diphenolase and monophenolase (of mushroom tyrosinase). $P$. boergesinii exhibited the most in vivo anti-tyrosinase activity compared with other samples.

$P$. boergesenii inhibited zebrafish tyrosinase more potent than kojic acid (83\% vs $50 \%$ inhibition for kojic acid). Moreover, it reduced melanin synthesis in zebrafish $42 \%$ (kojic acid: $50 \%)$.

Keywords: Algae; Persian Gulf; melanogenesis; mushroom tyrosinase; zebrafish.

\section{INTRODUCTION}

Melanin is one of the most widely distributed pigments in bacteria, fungi, plants and animals. The skin and hair color of mammals are determined by several factors. One of the most important factors is the degree and distribution of melanin pigments [1, 2]. The role of melanin is protecting the skin against UV radiations and reactive oxygen species (ROS) damages.

Tyrosinase (EC 1.14.18.1) is the key enzyme in the synthesis of melanin that catalyzes hydroxylation of L-tyrosine into L-Dopa (monophenolase activity) and its oxidation to dopaquinone (diphenolase activity). Multiple skin disorders, such as melasma, freckles, age-related and chemical-spots, resulted in excessive accumulation of melanin pigmentation in the skin [3]. There are various mechanisms for inhibiting melanogenesis. Tyrosinase inhibition is the most common method for reducing pigmentation in the skin[4].

In addition to the formation of melanin pigment, tyrosinase plays a role in browning of fruits, vegetables and sea foods. It oxidizes the phenols to the quinones and is responsible for the enzymatic browning of the damaged fruits during handling and storage. The produced quinones, in addition to the unpleasant odors and colors, may react irreversibly with amine and sulfide groups of proteins. The protein-quinone reaction decreases the digestibility of proteins and the amount of available essential amino acids, such as lysine and cysteine [1, 5, 6]. Furthermore, tyrosinase plays an important role in insect defense, wound healing, parasite capsule formation and external skeletal formation [7]. The available tyrosinase inhibitors such as hydroquinone have toxicity and low efficacy [8]. Therefore, researchers are looking for safer and more effective inhibitors like natural tyrosinase inhibitors for use in cosmetic and food industries to prevent or treat hyperpigmentasion disorders and browning reactions and as an alternative method for controlling insect pests.

The skin care effects such as whitening, sun protection, antioxidant, antibacterial, antifungal, moisturizing, anti-aging and anti-wrinkle were reported from brown algae[9]. Rucky coasts and proper environmental conditions in northern coasts of the Persian Gulf have created a suitable habitat for the growth and spread of macroalgae. Therefore, various species of brown macroalgae can be found in tidal zones of these areas [10]. Due to lack of reports on the effect of brown algae on the control of melanogenesis in Iran, the aim of this 
study was to investigate the beneficial skin care and inhibitory effects of the selected brown algae extracts on melanogenesis.

\section{MATERIAL AND METHODS Chemicals}

Mushroom tyrosinase (3130 unit/mg), L-DOPA (powder, $\geq 98.0 \%$ ), L-tyrosine (powder, $\geq 98.0 \%$ ), Synthetic melanin, DMSO (Dimethylsulfoxide) and methanol were purchased from Sigma Chemical Co (St.louis, MO, USA). Pro-prep and Pro-measure protein solutions were purchased from Intron Biotechnology (Korea). Kojic acid was obtained from Fluka and the other chemicals used were of analytical grades.

\section{Macroalgae Collection}

The brown seaweeds were collected at low tide time from the coastal areas of Bushehr. After harvesting, sands, salts and epiphytes were removed with fresh water and then, cut into appreciate size and were air-dried at room temperature with good-controlled air condition carefully. Samples were milled into powder and kept at $-80^{\circ} \mathrm{C}$ for further analysis. The voucher specimens were pressed and stored in $5 \%$ formol for identification. Morphological and anatomical examinations of cell structures were done for accurate identification with the aid of identification keys in the taxonomic publications [11-14].

\section{Algal Extracts Preparation}

Dried algal powder $(200 \mathrm{mg}$ ) was extracted with $6 \mathrm{~mL} 80 \%$ methanol in an ultrasonic bath for $30 \mathrm{~min}$, vortexed and then was kept at room temperature and dark place for $48 \mathrm{~h}$. After one more time vortexing, the extracts centrifuged at $10000 \mathrm{~g}$ for $15 \mathrm{~min}$, filtered through watman No.1 filter paper. After drying the extracts, the weight of dried extracts were calculated. Then, dried extracts were dissolved in 3\% DMSO and final dilutions of 100, 250 and $500 \mu \mathrm{g} / \mathrm{mL}$ were made.

\section{In Vitro: Mushroom Tyrosinase Inhibitory Assay}

The inhibitory effects of brown macroalgae were examined by cell-free mushroom tyrosinase assay as described by chan et al. [15] with minor modifications. The tyrosinase inhibitory activity was determined using L-Dopa and L-tyrosine as substrates. In brief, 100 $\mu \mathrm{L}$ of $200 \mathrm{unit} / \mathrm{ml}$ of mushroom tyrosinase in $25 \mathrm{mM}$ phosphate buffer $(\mathrm{pH} 6.8)$ was added to $50 \mu \mathrm{L}$ of various dilutions of extracts $(100,250$ and $500 \mu \mathrm{g} / \mathrm{mL})$ in 96 -well plate and the absorbance of wells were recorded at 70 - second intervals (10 cycles) at $475 \mathrm{~nm}$ with microplate reader (Tecan sunrise, Switzerland). This experiment was performed for measuring and correcting the interference of the excess absorbance of the phenolic compounds in the extract. Then, $100 \mu \mathrm{L}$ of L-Dopa $(2.5 \mathrm{mM})$ or L-tyrosine $(1.5 \mathrm{mM})$ were added to mixture reaction and absorbance was read at 70 -second intervals ( 20 cycles) at $475 \mathrm{~nm}$. Kojic acid $(50,100,250$ and $500 \mu \mathrm{g} / \mathrm{mL})$ and $3 \%$ DMSO were used as positive and negative controls, respectively.

Inhibitory activity of tyrosinase was calculated as:

$\%$ Inhibition $=\{[(A-B)-(C-D)] /(A-B)\} \times 100$

$A$ : Absorbance of the enzyme, substrate and DMSO solution. 
B: Absorbance of the substrate and DMSO solution.

C: Absorbance of the enzyme, substrate and extract solution.

D: Absorbance of the substrate and extract solution

\section{In Vivo Assay}

\section{Origin and Maintenance of Parental Zebrafish}

Adult zebrafish were purchased from a commercial dealer. Male and female zebrafish were kept in separate acrylic tanks at $28.5^{\circ} \mathrm{C}$ under the light/dark cycle of $14 / 10 \mathrm{~h}$. Zebrafish were fed 6 days a week and 3 times a day, with bloodworm food and supplemented with daphnia. In the evening, 6 fishes in 1: 2 ratio of female: male groups were transferred to $5 \mathrm{~L}$ tanks that have been marbled and filled with fresh water. By turning on the light in the morning, natural spawning was induced. The lucid fertilized eggs were collected for further experiments.

\section{Tyrosinase Inhibitory Activity Assay}

Tyrosinase inhibitory effects of brown macroalgae were determined spectrometrically as described previously by Choi et al. and Cha et al.[16, 17] with some modifications. In a 6-well plate, 100 embryos of the same age were added to each well containing $6650 \mu \mathrm{L}$ of sterile fresh water and were kept in incubator at $28.5^{\circ} \mathrm{C}$. After $9 \mathrm{hpf}$ (hours post fertilization), $350 \mu \mathrm{L}$ of the algal extracts $(100 \mu \mathrm{g} / \mathrm{mL})$ was added. Replacing the medium was done once a day to ensure uniform distribution of the compounds in the wells. After $48 \mathrm{hpf}$, zebrafish embryos were collected and sonicated in $6 \mathrm{~mL}$ pro-prep protein extraction solution in $15 \mathrm{~mL}$ falcon tube for extraction of enzyme and melanin. Lysate was removed by centrifuging at $10000 \mathrm{~g}$ for $5 \mathrm{~min}$. Supernatant was aspirated and pellet put aside for determination of melanin content. After quantitation of supernatant by pro-measure kit, the samples were adjusted by pro-prep solution to $250 \mu \mathrm{g} \mathrm{pr} / 100 \mu \mathrm{L}$. Then, $100 \mu \mathrm{L} 1.5 \mathrm{mM} \mathrm{L}$-tyrosine was added to $100 \mu \mathrm{L}$ of samples in 96-well plate and subsequently was incubated at $28^{\circ} \mathrm{C}$ for 60 minutes. Absorbance of samples was recorded at $475 \mathrm{~nm}$. The blank (containing $100 \mu \mathrm{L}$ of pro-prep solution and $100 \mu \mathrm{L}$ of $1.5 \mathrm{mM}$ L-tyrosine) absorbance was eliminated from each absorbance value. Kojic acid $(100 \mu \mathrm{g} / \mathrm{mL})$ and $0.1 \%$ DMSO were used as positive and negative controls, respectively. The final activity was expressed as a percentage to the negative control.

\section{Melanin content of zebrafish embryos}

The pellet was dissolved in $1 \mathrm{~mL}$ of $1 \mathrm{~N} \mathrm{NaOH}$ at $100{ }^{\circ} \mathrm{C}$ for $30 \mathrm{~min}$. The mixture was intensely vortexed to solubilize the melanin pigment. The absorbance of the supernatant was read at $490 \mathrm{~nm}$. NaOH was used as blank. Standard curve for synthetic melanin was obtained at concentration ranges between 1-300 $\mu \mathrm{g} / \mathrm{ml}$ (concentrations 1, 5, 10, 25, 50, 100, $200,300 \mu \mathrm{g} / \mathrm{mL}$ ). The melanin content was calibrated by protein amount, and expressed as a percentage to negative control. 
Experiments were carried out in triplicate and the data were expressed as the mean \pm standard error. One-way ANOVA was used to compare the mean values of each treatment. $A$ value of $P<0.05$ was considered as statistically significant in all experiments.

\section{RESULTS}

In this study, 17 samples of brown algae were collected. Algae were identified using valid sources and keys by morphological characteristics. The species, location and time of collection are listed in Table 1.

Table1. Seaweeds and their location and collection time.

\begin{tabular}{|c|c|c|c|c|}
\hline $\begin{array}{l}\text { Herbarium } \\
\text { Code }\end{array}$ & $\begin{array}{l}\text { Sample } \\
\text { Code }\end{array}$ & Species & Location & $\begin{array}{l}\text { Collection } \\
\text { time }\end{array}$ \\
\hline B100211 & $\mathrm{Pa}$ & Padina australis & Halileh & December \\
\hline B131111 & $\mathrm{Pb}$ & Padina boergesenii & Jofreh & February \\
\hline B131311 & $\mathrm{Pd}$ & Padina distromatica & Gheshm & May \\
\hline B131312 & $\mathrm{Pt}$ & Padina tetrastromatica & Gheshm & May \\
\hline B110611 & Cs1 & Colpomenia sinuosa & Haleh & March \\
\hline B110211 & Cs2 & Colpomenia sinuosa & Halileh & March \\
\hline B131411 & Cs3 & Colpomenia sinuosa & Southern Ouli & February \\
\hline B131121 & Cs4 & Colpomenia sinuosa & Jofreh & February \\
\hline B100311 & Ct1 & Cystoseira trinodis & Rostami & December \\
\hline B131131 & Ct2 & Cystoseira trinodis & Jofreh & February \\
\hline B100322 & Sa1 & Sargassum angustifolium & Rostami & December \\
\hline B131211 & Sa2 & Sargassum angustifolium & Nirue havaee & February \\
\hline B110312 & Sc & Sargassum crassifolium & Rostami & October \\
\hline B110311 & $\mathrm{Sg}$ & Sargassum glaucescens & Rostami & October \\
\hline B100321 & Ss 1 & Sargassum swartzii & Rostami & December \\
\hline B130311 & Ss2 & Sargassum swartzii & Rostami & February \\
\hline B110313 & St & Sargassum tenerrimum & Rostami & October \\
\hline
\end{tabular}

The percent of inhibition of algae on L-Dopa oxidation by mushroom tyrosinase was calculated at three concentrations of 500,250 and $100 \mu \mathrm{g} / \mathrm{mL}$. $P$. boergesinii showed the highest inhibitory activity compared to other seaweeds, but its activity was lower than that of kojic acid as positive control. The percentage of inhibition of samples is shown in Table 2.

Table 2. Percent inhibitory effects of algae on oxidation of L-Dopa by mushroom tyrosinase. Each value is expressed as the mean $\pm S E(n=3)$. 


\begin{tabular}{|c|c|c|c|c|}
\hline Sample Code & Species & & $\begin{array}{l}\text { Conc } \\
(\mu \mathrm{g} / \mathrm{mL})\end{array}$ & \\
\hline & & 100 & 250 & 500 \\
\hline $\mathrm{Pa}$ & P. australis & $3.83 \pm 0.21$ & $9.80 \pm 0.42$ & $12.63 \pm 0.82$ \\
\hline $\mathrm{Pb}$ & P. boergesenii & $17.63 \pm 0.56$ & $36.68 \pm 1.03$ & $51.75 \pm 0.69$ \\
\hline $\mathrm{Pd}$ & P. distromatica & $8.52 \pm 1.02$ & $9.57 \pm 0.99$ & $10.02 \pm 0.54$ \\
\hline $\mathrm{Pt}$ & P. tetrastromatica & $8.43 \pm 0.84$ & $12.35 \pm 0.39$ & $18.48 \pm 1.24$ \\
\hline Cs1 & C. sinuosa & $7.66 \pm 1.13$ & $10.88 \pm 0.93$ & $12.81 \pm 0.65$ \\
\hline Cs2 & C. sinuosa & $7.87 \pm 1.01$ & $9.92 \pm 0.73$ & $10.10 \pm 0.81$ \\
\hline Cs3 & C. sinuosa & $12.34 \pm 0.78$ & $13.84 \pm 1.02$ & $23.25 \pm 0.91$ \\
\hline Cs4 & C. sinuosa & $15.90 \pm 1.02$ & $17.61 \pm 0.93$ & $20.27 \pm 1.53$ \\
\hline Ct1 & Cystoseira trinodis & $17.21 \pm 1.33$ & $15.10 \pm 0.72$ & $15.22 \pm 0.69$ \\
\hline Ct2 & Cystoseira trinodis & $14.45 \pm 0.78$ & $15.31 \pm 1.08$ & $18.46 \pm 0.79$ \\
\hline Sa1 & S. angustifolium & $5.23 \pm 0.94$ & $10.35 \pm 0.67$ & $10.62 \pm 0.45$ \\
\hline $\mathrm{Sa} 2$ & S. angustifolium & $10.74 \pm 0.6$ & $12.58 \pm 1.03$ & $13.28 \pm 0.91$ \\
\hline Sc & S. crassifolium & $5.71 \pm 0.72$ & $8.78 \pm 0.11$ & $13.12 \pm 0.89$ \\
\hline $\mathrm{Sg}$ & S. glaucescens & $3.68 \pm 0.47$ & $5.64 \pm 0.82$ & $10.52 \pm 0.71$ \\
\hline Ss 1 & S. swartzii & $13.38 \pm 1.02$ & $20.04 \pm 1.31$ & $20.55 \pm 0.54$ \\
\hline Ss2 & S. swartzii & $6.79 \pm 0.88$ & $7.95 \pm 0.23$ & $10.60 \pm 0.67$ \\
\hline \multirow[t]{2}{*}{ St } & S. tenerrimum & $11.61 \pm 0.96$ & $11.99 \pm 0.77$ & $14.35 \pm 1.05$ \\
\hline & Kojic acid & $81.85 \pm 1.52$ & $92.33 \pm 0.87$ & $93.54 \pm 0.67$ \\
\hline
\end{tabular}

P. boergesenii, C. sinuosa (Cs3, Cs4) and S. swartzii (Ss2) showed the highest inhibitory effects on L-Dopa oxidation by mushroom tyrosinase, and therefore, were selected to investigate the inhibitory effect on monophenolase activity of mushroom tyrosinase and in vivo studies.

All algae showed anti-tyrosinase activity on monophenolase activity less than kojic acid. S. swartzii did not inhibit tyrosinase activity and $P$. boergesenii exhibited the highest percentage of tyrosinase inhibition (Table 3). 
Table 3. Percent inhibitory effects of selected algae on hydroxylation of L-tyrosine by mushroom tyrosinase. Each value is expressed as the mean $\pm S E(n=3)$.

\begin{tabular}{lcccc}
\hline \multicolumn{1}{c}{ Species } & \multicolumn{5}{c}{ Tyrosinase } & inhibition \\
& $50 \mu \mathrm{g} / \mathrm{mL}$ & $100 \mu \mathrm{g} / \mathrm{mL}$ & $250 \mu \mathrm{g} / \mathrm{mL}$ & $500 \mu \mathrm{g} / \mathrm{mL}$ \\
P. boergesenii (Pb) & $\mathrm{NT}^{1}$ & $46.46 \pm 1.29$ & $78.58 \pm 1.12$ & $99.61 \pm 0.51$ \\
C. sinuosa (Cs3) & $\mathrm{NT}$ & $11.80 \pm 1.06$ & $13.97 \pm 1.41$ & $20.51 \pm 1.23$ \\
C. sinuosa (Cs4) & $\mathrm{NT}$ & $9.44 \pm 0.59$ & $11.25 \pm 1.01$ & $13.61 \pm 1.31$ \\
S. swartzii (Ss2) & $\mathrm{NT}$ & $\mathrm{NI}^{2}$ & $\mathrm{NI}$ & $1.10 \pm 0.10$ \\
Kojic acid & $94.55 \pm 1.52$ & $99.65 \pm 0.42$ & 100 & 100 \\
${ }^{1} \mathrm{NT}$ : Not Tested & & & & \\
${ }^{2} \mathrm{NI}$ : No Inhibition & & &
\end{tabular}

To ensure the consistency of the in vitro assay results (mushroom tyrosinase) with in vivo model, the inhibitory effects of selected algae were investigated on melanin synthesis and tyrosinase activity of zebrafish. The percentage of inhibition of algal extracts at $100 \mu \mathrm{g} / \mathrm{mL}$ was calculated by using L-tyrosine as a substrate. $P$. boergesenii exhibited the highest inhibitory activity compared to kojic acid and the other algae (83.09 \pm 1.53 vs $50.45 \pm 0.86$ for kojic acid), followed by two samples of $C$. sinuosa (Cs3, Cs4) that were close to that of kojic acid (Table 4). Significant difference $(P<0.05)$ was observed between kojic acid and all tested algae on melanin synthesis reduction (Table 4).

Table 4. Percent inhibitory effects of algae on monophenolase activity of zebrafish tyrosinase and melanin synthesis at $100 \mu \mathrm{g} / \mathrm{mL}$. Each value is expressed as the mean $\pm S E(n=3)$.

\begin{tabular}{lcc}
\hline \multicolumn{1}{c}{ Species } & Tyrosinase activity & Melanin synthesis \\
\hline & & \\
P. boergesenii (Pb) & $83.09 \pm 1.53$ & $41.95 \pm 1.74$ \\
C. sinuosa (Cs3) & $43.28 \pm 1.59$ & $27.74 \pm 1.06$ \\
C. sinuosa (Cs4) & $41.98 \pm 0.78$ & $18.31 \pm 1.06$ \\
S. swartzii (Ss2) & $24.37 \pm 1.53$ & $19.73 \pm 0.89$ \\
Kojic acid & $50.45 \pm 0.86$ & $50.21 \pm 1.27$ \\
\hline
\end{tabular}

\section{DISCUSSION}

In this study, we investigated anti-melanogenesis of 17 brown macroalga using in vitro and in vivo models. $P$. boergesenii exhibited higher in vitro anti- tyrosinase activity (monophenolase and diphenolase activities of mushroom tyrosinase) compared to other algae. Its ability to inhibit melanin synthesis was lower than that of kojic acid (42\% versus $50 \%$ )but was higher in comparison to the other tested algae. In previous studies, the anti-tyrosinase effect of Padina seaweed have been reported. Quah et al., studied on ethanolic extract of $P$. tenuis in all various tested concentrations $(10-1000 \mu \mathrm{g} / \mathrm{mL})$ which showed tyrosinase's diphenolase inhibitory activity. They also reported that the hexane fraction of the $P$. tenuis extract was able to inhibit HEM (human epidermis melanocyte) proliferation in vitro and reduce melanin synthesis in guinea pigs exposed to UVB radiation 
without any dermal irritation during the treatment [18]. Tyrosinase's diphenolase inhibitory activity of $P$. distromatica and $P$. australis in present work showed some similarity with that of $P$. teunis in the mentioned work. $P$. boergesenii inhibited the monophenolase activity of mushroom tyrosinase more than diphenolase activity (46.46\% vs $17.63 \%)$. Algae that can inhibit both monophenolase and diphenolase tyrosinase activities are more potent inhibitors. Cha et al. reported that extract of $P$. arborescens $(100 \mu \mathrm{g} / \mathrm{mL})$, has inhibited monophenolase activity of tyrosinase enzyme by $17 \%$. In our study, $P$. boergesenii $(100 \mu \mathrm{g} /$ $\mathrm{mL}$ ), inhibited monophenolase tyrosinase activity by $46 \%$, indicates that $P$. boergesenii is a stronger inhibitor in comparison to $P$. arborescens[16]. In previous studies, antioxidant, antibacterial, antifungal and anti-melanogenesis effects of $P$. boergesenii have been reported [19-22]. The anti-melanogenic effect of $P$. boergesenii is probably due to the presence of fucoxanthin, fucoidan, phenolic and terpene compounds. Fucoidan had a competitive inhibitory effect on the tyrosinase enzyme in the oxidation of tyrosine. It also has anti-aging effects[23].

UV is the main cause of damage to cellular components and some skin diseases such as hyperpigmentation, weakness, wrinkles, erythema and skin cancer. Over exposure to UV radiations results in ROS production, leading to enhance melanin synthesis, DNA damage, proliferation of melanocytes, inflammatory reactions and skin angiogenesis. Thus, ROS scavenging compounds and redox agents like antioxidants are effective in the treatment of hyperpigmentation and other UV-mediated disorders[24]. Heo et al. showed that fucoxanthin significantly reduced the production of ROS by UVB rays in human fibroblasts. Fucoxanthin increases cell survival and reduces cellular damage, suggesting that fucoxanthin can protect the skin from UVB damage [25]. Shimode et al. showed that fucoxanthin reduced tyrosinase activity, melanogenesis in melanoma cells, and UVB-induced pigmentation. It also significantly reduced the expression of COX-2, endothelin A receptors, p75 neurotrophin, melanocortin-1 and tyrosinase-related protein 1[26]. Urikura et al. exhibited that fucoxanthin significantly inhibited the UVB-induced epidermis hypertrophy, which may lead to wrinkles, as well as the vascular endothelial growth factor and the expression of the matrix metalloproteinase-13. Also, their results showed that topical treatment of fucoxanthin reduced the aging of the skin caused by sunlight and wrinkles in mice exposed to UVB radiation [27]. Compounds with reduction potential like antioxidants can have anti-tyrosinase effects through two ways: by interacting with $O$-quinones, and suppression of the oxidative polymerization of melanin intermediates or by tyrosinase inhibition through reacting with copper in the active site of the enzyme[28]. Fucoidan is a sulfated polysaccharide that could react with copper through sulfide atom. The antioxidant effect of $P$. boergesenii is another mechanism involved in reducing the synthesis of melanin [23].

In this study, the anti-tyrosinase potential of seven samples of the seaweed Sargassum was investigated. S. swartzii showed most inhibitory effect on L-Dopa oxidation compared to other algae in this genus. Other algae had approximately the same effects on inhibition of the enzyme (3-14\% in the range of tested concentrations). Concentrations of 250 and 500 $\mu \mathrm{g} / \mathrm{mL}$ of $S$. swartzii exhibited relatively similar inhibitory effects (Table 2). Several studies have been shown the anti-tyrosinase effects of Sargasum Sp [15-16, 18, 29-30]. For instance, Cha et al., reported that $S$. siliquastrum was one of four strong algae among 43 
tested algae, with a relatively low $\mathrm{IC}_{50}$ value of $19.85 \mu \mathrm{g} / \mathrm{mL}$. S. siliquastrum also inhibited tyrosinase and melanin synthesis in melanocyte B16 cells. S. siliquastrum $(100 \mu \mathrm{g} / \mathrm{mL})$, inhibited monophenolase tyrosinase activity and melanin synthesis in zebrafish by $50 \%$. Propylthiouracil (PTU) $(0.2 \mathrm{mmol} / \mathrm{L})$ and arbutin $(20 \mathrm{mmol} / \mathrm{L})$ exhibited anti-tyrosinase activity by $69 \%$ and $57 \%$ and anti-melanogenesis potential by $72 \%$ and $61 \%$ respectively in zebrafish [16]. In our study, kojic acid $(100 \mu \mathrm{g} / \mathrm{mL})$ reduced monophenolase tyrosinase activity and melanin synthesis in zebrafish by $50.45 \%$ and $50.21 \%$, respectively. S. swartzii showed minimum inhibitory activity among the other seaweeds $(24.37 \%$ and $19.73 \%$ at concentration of $100 \mu \mathrm{g} / \mathrm{mL}$, respectively). S. swartzii inhibited the monophenolase activity of zebrafish tyrosinase more than mushroom tyrosinase at $100 \mu \mathrm{g} / \mathrm{mL}$ ( $24 \%$ vs no inhibition). Chan et al. showed that ethanolic extract and hexane, ethyl acetate and water fractions of $S$. polycystum exhibited little activity on mushroom tyrosinase, but the ethanolic extract and hexane fraction significantly inhibited the B16F10 mouse melanoma cells tyrosinase. In addition, hexane fractions reduced the production of melanin in B16F10 cells [15]. The ethanolic extracts and hexane fractions of $S$. polycystum had a higher toxicity on HEM cells than normal cells. Local administration of $S$. polycystum cream for three weeks reduced the production of melanin in Indian guinea pigs [18].

S. swartzii collected from Rostami in December (Ss1) showed more inhibitory activity when compared with the sample collected in February (Ss2). Farasat et al. showed that the sampling time had a significant effect on antioxidant capacity, content of phenol and flavonoids of green seaweeds. Temperature variations activate the defensive compounds such as antioxidant enzymes and molecules such as ascorbic acid. Environmental changes can affect the metabolism and the type of bioactive compounds of algae [30]. Likewise padina, the anti-tyrosinase effect of Sargasum seaweed is probably related to the compounds such as fucoidan and fucoxanthin.

The results of the anti-tyrosinase activity of $C$. sinuosa collected from different places in February and March indicate that the collection time has more effect on secondary metabolites compared to collection places. In a study by $\mathrm{CHA}$ et al., $\mathrm{C}$. sinuosa collected from Jeju Island in February to May at concentration of $100 \mu \mathrm{g} / \mathrm{mL}$ inhibited monophenolase tyrosinase activity by about $31 \%$, while in our study, the algal samples from Jofreh and Southern Ouli in February showed inhibitory effects $9-12 \%$. These results show that the location of collection due to the different environmental conditions, the type of bed, etc., influence on inhibition potency [16]. Farasat et al. showed that the collection site significantly affects the antioxidant capacity, and also the amount of phenols and flavonoids. Therefore, the time and place of collection, can affect the anti-melanogenic activity through changing the antioxidant capacity [31].

Two samples of the same species, C. sinuosa from two locations (Cs3, Cs4) showed relatively similar inhibitory effects on hydroxylation of L-tyrosine by the zebrafish tyrosinase enzyme. Their effects on synthesis of melanin were slightly different. $C$. sinuosa (Southern Ouli, Cs3) showed more inhibitory effect on melanin synthesis in comparison to $C$. sinuosa (from Jofreh, Cs4). The tyrosinase inhibitory effect of $C$. sinuosa may be due to the presence of phlorotanins. The antioxidant effect of $C$. sinuosa through the reduction of quinone products can play a role in inhibiting the synthesis of melanin [32]. In general, these results 
indicate that the type of algae as well as the place of collection or even collection time can affect the inhibitory activities.

In this study $P$. boergesenii showed the most anti-tyrosinase activity that can be considered as a promising seaweed for using in skin care formulations, especially whitening agents. However, further investigations on $P$. boergesenii may lead to identify bioactive compounds responsible for anti-tyrosinase effects.

Funding: This research received no external funding.

Acknowledgments: The authors are grateful to the Marine Pharmaceutical Research Center of Ahvaz Jundishapur University of Medical Sciences.

Conflicts of Interest: We have no conflict of interest.

\section{REFERENCES}

1. Kim, YJ.; Uyama, H. Tyrosinase inhibitors from natural and synthetic sources: Structure, inhibition mechanism and perspective for the future. Cell Mol Life Sci 2005, 62(15), 1707-1723.

2. Kollias, N.; Sayre, RM.; Zeise, L.; Chedekel, MR. New trends in photobiology: Photoprotection by melanin. J Photochem Photobiol 1991, 9(2), 135-160.

3. Chang, TS. An updated review of tyrosinase inhibitors. Int J Mol Sci 2009, 10(6), 2440-2475.

4. Solano, F.; Briganti, S.; Picardo, M.; Ghanem G. Hypopigmenting agents: An updated review on biological, chemical and clinical aspects. Pigment Cell Res 2006, 19(6), 550-571.

5. Loizzo, M.; Tundis, R.; Menichini F. Natural and synthetic tyrosinase inhibitors as antibrowning agents: an update. Compr Rev Food Sci Food Saf 2012, 11(4), 378-398.

6. Palma, MSA.; Horn, H.; Zilli, M.; Pigatto, G.; Converti, A. A new enzymatic process for the treatment of phenolic pollutants. Braz. Arch. Bio.Technol 2013, 56(4), 653-662.

7. Sugumaran, M.; Nellaiappan, K.; Amaratunga, C.; Cardinale, S.; Scott T. Insect Melanogenesis: III. Metabolon Formation in the Melanogenic Pathway-Regulation of Phenoloxidase Activity by Endogenous Dopachrome Isomerase (Decarboxylating) from Manduca sexta. Arch Biochem Biophys 2000, 378(2), 393-403.

8. Germanas, JP.; Wang, S.; Miner, A.; Hao, W.; Ready, JM. Discovery of small-molecule inhibitors of tyrosinase. Bioorganic Med Chem Lett 2007, 17(24), 6871-6875.

9. Kim, S-K. Marine Cosmeceuticals: Trends and Prospects; CRC Press, 2012.

10. Rouhani ghadikolaei, K.; Hosseini, M. Investigating distribution and biomass of two species of brown algae (Colpomenia sinousa and lyngaria stellata) in costal waters of Hormozgan province, sothern Iran. Iran J Sci fish 2005, 13(4), 55-64.

11. Silva, P.C.; Basson, P.W.; Moe, R.L. Catalogue of the Benthic Marine Algae of the Indian Ocean; University of California Publications in Botany, 1996.

12. Jha, B.; Reddy, CRK.; Thakur, MC.; Rao, MU. Seaweeds of India, The Diversity and Distribution of Seaweeds of the Gujarat Coast, 1st ed.; Springer Netherlands, 2009.

13. Teo, LW.; Wee, YC. Seaweeds of Singapore; Singapore University Press: Singapore, 1983.

14. Nam, K.; Saito, Y. Anatomical characteristics of Laurencia papillosa (Rhodomelaceae, Rhodophyta) from Guam and Palau. Micronesica 1991, 24(1), 87-94. 
15. Chan, Y.; Kim, K.; Cheah, S. Inhibitory effects of Sargassum polycystum on tyrosinase activity and melanin formation in B16F10 murine melanoma cells. $J$ ethnopharmacol 2011, 137(3), 1183-1188.

16. Cha, SH.; Ko, SC.; Kim, D.; Jeon, YJ. Screening of marine algae for potential tyrosinase inhibitor: those inhibitors reduced tyrosinase activity and melanin synthesis in zebrafish. $J$ Dermatol 2011, 38(4), 354-363.

17. Choi, TY.; Kim, JH.; Ko, DH.; Kim, CH.; Hwang, JS.; Ahn, S.; et al. Zebrafish as a new model for phenotype-based screening of melanogenic regulatory compounds. Pigment Cell Res 2007, 20(2), 120-127.

18. Quah, CC.; Kim, KH.; Lau, MS.; Kim, WR.; Gundamaraju, R.; Gundamaraju, R. Pigmentation and dermal coservative effects of the astonishing algae Sargassum polycystum and Padina tenuis on guinea pigs, human epidermal melanocytes(HEM) and chang cells. Afr J Tradit Complement Altern Med 2014, 11(4), 77-83.

19. Ravikumar, S.; Anburajan, L.; Ramanathan, G.; Kaliaperumal, N. Screening of seaweed extracts against antibiotic resistant post operative infectious pathogens. Seaweed Res Utiln 2002, 24(1), 95-99.

20. Permeh, P.; Gohari, A.; Saeidnia, S.; Jamili, S.; Permeh, S.; Mostafavi, PG. Alpha amylase inhibitory and Antioxidant activity of Padina boergesenii (Allander and Kraft) from Persian Gulf. Planta Medica, 79(13), PA31.

21. Arul Senthil, K.; Rajesh, P.; Murugan, A. Antibacterial activity of the crude extracts of the seaweed Padina boergesenii. Seaweed Res Utiln 2008, 30, 177-182.

22. Shola, TA.; Wins, JA.; Murugan, M. Screening on bioactive compounds of selected marine seaweeds and its antifungal activity. Int J Res Eng Biosci 2014, 2(1).

23. Yu, P.; Sun H. Purification of a fucoidan from kelp polysaccharide and its inhibitory kinetics for tyrosinase. Carbohydr polym 2014, 99, 278-283.

24. Wang, KH.; Lin, RD.; Hsu, FL.; Huang, YH.; Chang, HC.; Huang, CY.; et al. Cosmetic applications of selected traditional Chinese herbal medicines. J Ethnopharmacol 2006, 106(3), 353-359.

25. Heo, S-J.; Jeon, Y-J. Protective effect of fucoxanthin isolated from Sargassum siliquastrum on UV-B induced cell damage. J Photochem Photobiol 2009, 95(2), 101-107.

26. Shimoda, H.; Tanaka, J.; Shan, SJ.; Maoka, T. Anti-pigmentary activity of fucoxanthin and its influence on skin mRNA expression of melanogenic molecules. J Pharm Pharmacol 2010, 62(9), 1137-1145.

27. Urikura, I.; Sugawara, T.; Hirata T. Protective effect of fucoxanthin against UVB-induced skin photoaging in hairless mice. Biosci Biotech Biochem 2011, 75(4), 757-760.

28. Briganti, S.; Camera, E.; Picardo, M. Chemical and instrumental approaches to treat hyperpigmentation. Pigment Cell Res 2003, 16(2), 101-110.

29. Kang, HS.; Kim, HR.; Byun, DS.; Son, BW.; Nam, TJ.; Choi, JS. Tyrosinase inhibitors isolated from the edible brown alga Ecklonia stolonifera. Arch Pharm Res 2004, 27(12), 1226-1232.

30. Heo, SJ.; Ko, SC.; Kang, SM.; Cha, SH.; Lee, SH.; Kang, DH.; et al. Inhibitory effect of diphlorethohydroxycarmalol on melanogenesis and its protective effect against UV-B radiation-induced cell damage. Food Chem Toxicol 2010, 48(5), 1355-1361. 
31. Zang, J.; Chen, Z-h.; Ye, S.; Si, Y-x.; Li, C-y. Study on inhibition effect of Sargassum fusiforme polysaccharide extracts on activity of tyrosinase. Sci Technol Food Indust 2012, 20, 27.

32. Farasat, M.; Khavari-Nejad, R-A.; Nabavi, SMB.; Namjooyan, F. Antioxidant properties of some

filamentous green algae (Chaetomorpha Genus). Braz. Arch. Biol. Technol 2013, 56(6), 921-927.

33. Heo, S.; Cha, S.; Lee, K.; Cho, SK.; Jeon, Y. Antioxidant activities of chlorophyta and phaeophyta from Jeju Island. Algae 2005, 20(3), 251.

(C) 52018 by the authors. Submitted for possible open access publication
under the terms and conditions of the Creative Commons Attribution (CC
BY NC) license (https://creativecommons.org/licenses/by-nc/4.0/). 